Trata-se de uma reflexão sobre as realizaçōes, os tropeços e as

(im)possibilidades de quem ousa fazer marcas sobre o brincar infantil. Comentase um estudo sobre o tema que vai da psico(bio)logia do jogo infantil (através da análise das teorias clássicas do jogo infantil de Stanley Hall e Karl Groos e prevendo filiações teóricas com certas posições atuais) à psicanálise (que defende ser o brincar infantil um faz-de-conta que é adulto, sendo a antecipação possível de um desejo que percorre toda a infância: ser adulto e entender o desejo que anima o mundo dos adultos).

Jogo; brincar infantil; fazer de conta; psicologia; psicanálise

FROM THE "SING DRAMA" TO THE DANCE OF THE "BUNDINHA": PLAYING IS A MAKE-BELIEVE ESSENTIALLY ADULT, LIVING IN A WORLD WHICH IS GOVERNED BY DESIRE?

This paper is about the achievements, pit-falls and (im)possibilities experienced by those who dare to make "pit" about

children's games. A scientific paper, which starts with the psycho(bio)logy of children's games (pasting from an analysis of Stanley Hall and Karl Groos classic theories on children's games and anticipating affiliations as far as theory goes with certain present positions) and reaches up to psychoanalysis (which defends the position that children's playing constitutes a make-believe essentially adult, possibly being an anticipation of a desire which may be traced through the entire childhood: to be adult and to understand the desire which animates the adult world).

Games; children's playing; make-believe; psychology; psychoanalysis

\section{DO DRAMA \\ CANTADO À DANÇA DA BUNDINHA: BRINCAR É FAZER DE CONTA QUE É ADULTO?}

Maria da Glória Feitosa Freitas

"O homem deixou o filho num cisco e saiu de a pé comendo fruta no mato. Tem certidão desse homem por tudo quanto. É vereda. Tem tapera e osso de caititu por tudo quanto. É lugar" Manuel de Barros, Arranjos para assobio<smiles>[Z]c1ccccc1</smiles>
ossa reflexão sobre o brincar infantil tenta percorrer as realizações, os tropeços e as (im)possibilidades de quem ousa fazer "marcas" sobre esse tema. Estudamos o jogo infantil, da psico(bio)logia do jogo infantil (ou seja, de algumas teorias psicológicas do jogo infantil) ao desejo de fazer de conta que se é adulto (à concepção da psicanálise sobre o brincar infantil).

Pedagoga; mestre em Educação pela USP, proła da Universidade Estadual Vale do Acaraú (Sobral, CE). 
Ao longo de nossa trajetória em torno do tema, fomos nos questionando. É possível que determinismos psico(bio)lógicos contidos em certas teorias sobre o jogo infantil "patrocinem" certas posições e práticas dos adultos diante das horas de brincar das crianças contemporâneas?

A certa altura do "jogo", suspeitamos que seria possivel a esses determinismos serem mais bem entendidos por meio do conhecimento histórico do que representou transformar um saber (o saber psicológico) em ciência moderna (a psicologia, a partir de Wundt). Sendo assim, "pulamos" para dentro da história da psicologia e repensamos nossas certezas iniciais. No começo do "campeonato", acreditávamos que era possível transformar jogos infantis em método de ensino. E o primeiro passo dado foi coletar um "arsenal" de jogos infantis dignos de qualquer Itard dedicado a cientificar as "coisas" mais simples da vida.

Fomos nos questionando, aos poucos: a nossa insistência em realizar a criação de mais um método "novo" para estimular capacidades maturacionais das crianças de Guriú (localidade do litoral oeste cearense) não era o resultado de nosso condicionamento ao pensar psicológico, feito ciência a partir do século XIX?

Desejávamos construir mais um método "salvador" das mazelas que o fracasso escolar causa às crianças (mais especificamente às crianças de Guriú). O que queríamos? Era realizar a possibilidade de uma prática educativa em que nada pudesse faltar?

Diante da "desilusão" (acontecida aos poucos...) com métodos que salvam qualquer prática pedagógica do fracasso escolar, pensamos que talvez a história do pensamento psicológico poderia explicar a origem das crenças que aos poucos fomos abandonando.

Igual a um jogo de "esconde-esconde", ocupamos o lugar de quem faz a busca dos ocultos "ingredientes" que nos impregnaram da vontade de "cientificar" as práticas educativas de uma pequena praia - Guriú.

Era a caça aos condicionantes da "obsessão" contemporânea de usar as brincadeiras infantis em prol de um desenvolvimento de capacidades maturacionais certas e esperadas. Em determinado momento deixamos de acreditar que as brincadeiras precisam ser transformadas em atividades programadas em prol do desenvolvimento de uma capacidade específica.

Partimos para a realização de uma análise da influência biológica contida nas teorias psicológicas sobre o brincar infantil, que movem desejos idênticos aos nossos desejos iniciais: transformar as brincadeiras em técnicas educacionais, e que reificam o brincar.

Conhecidas as origens desses condicionantes, acreditamos que entenderíamos melhor a ortopedização do brincar, os métodos lúdicos 
que usou Itard (no século XIX) com o "selvagem" Victor e demais cientistas do jogo infantil, o "fim" (?) dos brinquedos manufaturados por e com o amor dos adultos amados pelas crianças, e as somas que são gastas para produzir brinquedos, comprovados e cientificamente testados e aprovados, como fator primordial do pleno desenvolvimento natural (que pode ser visto como idêntico a todos; não prevê vicissitudes, só a estimulação de funções).

O comando moderno parece ser: e, se algo funcionar mal, vale duplicar a dose necessária de estimulações diárias, à moda de Itard e Schreber (ambos do século XIX) (Mannoni, 1977, p.32; Itard, 1988, p.157). Com brinquedos ou brincadeiras infantis orientados!

Nesse verdadeiro jogo de "pega-pega", por entre os dados da história da psicologia, deparamos com um discurso tão aliado à biologia, para se fazer ciência, que resolvemos dar-lhe o "pseudônimo" de psico(bio)logia, ciência que reifica as emoções, e torna a nossa existência um previsível acontecer, controlável e sem incertezas.

Compreendendo os condicionantes da psicologia, visitamos os ideários de Karl Groos e Stanley Hall, dois clássicos pensadores da Psicologia do Jogo, representantes dos séculos XIX e XX respectivamente; e exercitamos um certo "rastreamento" das semelhanças de suas obras com relação às publicações recentes sobre o brincar (mesmo que eles não sejam diretamente lançados como inspiradores das modernas concepções sobre as manifestações lúdicas infantis).

A nossa intenção era investigar a possibilidade de uma certa “filiação" entre certas posições correntes e duas posições dentro da Psicologia do Jogo, que limitam o brincar infantil por significá-lo como algo que pré-exercita funções (Groos) ou é herança instintiva dos antepassados (Stanley Hall) (Linaza, 1992).

E atual estimular capacidades maturacionais com jogos infantis, é moderno entregar brinquedos a serem consumidos em uma específica faixa etária, está em voga transformar as brincadeiras em metodologia. E, até onde caminhamos, Karl Groos e Stanley Hall não são lembrados como figuras inspiradoras. Acreditamos estarem recalcados, porém vivos nessas práticas!

Observando alguns livros atuais sobre o jogo infantil, propomos que há uma certa filiação simbólica entre esses modernos manuais e o pensamento de Itard, Groos e Stanley Hall. Sendo um cientista do século XIX, Itard obriga o pobre Victor a suportar situações "lúdico-pedagógicas" parecidas com as descritas em alguns lançamentos editoriais festejados (Malson, 1980, p.157).

Ousamos propor que a atitude de empurrar jogos com objetivos "educativos" bem definidos ao pequeno Victor não é tão distinta de certas descrições denominadas construtivistas e que mais parecem ter saído da cabeça de Itard. Que por sinal nem é lem- 
brado. Supomos que o pai de tudo isso é bem mais Itard do que qualquer construtivista que a história tenha nos feito conhecer.

É possível compreender que Itard proponha a ortopedização do brincar. Ele havia casado com a ciência novecentista, estava longe do que deveria ser um pai, em qualquer tempo da história.

Já os pais modernos, apaixonados pela tecnologia, são diferentes ou parecem mais cientistas do século XIX, replicantes de Itard, ou consumidores das maravilhosas criações lúdicas dos Itards atuais?

Encontrados prontos nas lojas, os brinquedos perderam aquele algo mais que nossos entrevistados de Guriú nos narraram (e que lá mesmo se vai também perdendo...): o amor de quem os fez e o brilho nos olhos de quem os recebe e não mais os esquece.

Por que nós, as companhias adultas das crianças, nos destituímos desse lugar junto ao brincar infantil? Por que obedecemos, tão-somente, aos ditames da ciência? Por que julgamos que os especialistas sabem mais do que os pais, educadores e demais "acompanhantes” da infância? Por que acreditamos tanto nas vantagens do jogo infantil para o desenvolvimento de capacidades maturativas $e$ do seu uso em metodologias eficazes contra o fracasso escolar, que pipocam aqui e ali, nos quatro cantos do planeta?

Realizamos junto ao brincar das crianças que estão sob a nossa responsabilidade algo parecido com atitudes que retiram as responsabilidades sobre nossas dores. É bom lembrar que somos as presas de fácil captura dos remédios à prova de qualquer sintoma, dos reeducadores capazes de combater quaisquer fracassos escolares, das técnicas infalíveis para curar qualquer enxaqueca, de truques inquestionáveis para deixar de fumar... assim, as dificuldades para viver (adeus, mal-estar!) são superadas.

A brincadeira é enlatada, encaixotada, normatizada e vendida em supermercados. Livros ensinam as crianças a brincar e, aos adultos, o que deve ser um pai moderno (aquele que compra as novidades? Alguém que abdica de um "antigo" lugar de construtor de brinquedos?).

Nessa nossa caminhada pelos domínios da Psicologia do Jogo foi possível compreender que algumas teorias levam à crença na possibilidade de estimular capacidades maturacionais com o uso de jogos infantis metodicamente preparados.

Os adultos que assim agem são considerados portadores de idéias avançadas! São dignos da titulação de "modernos". Sendo assim, pais modernos não se arriscam a construir brinquedos de lata, mas engajam-se nas tarefas de comprar e entregar aos seus filhos os brinquedos a serem consumidos em uma faixa etária específica, e de um modo já prescrito.

No mercado das ilusões, dá-se um jeito em tudo! Enquanto os adultos fracassam ou renunciam a seus papéis de educadores (La- 
jonquière, 1997, p.27-43), as crianças fazem o que já faziam os nossos entrevistados (hoje idosos): brincam para entender o mundo que querem habitar, ou seja, o mundo dos adultos (e conseguir saber sobre o desejo que os anima). Assim julgava Freud e a psicanálise.

Voltando a pensar em Guriú há mais de 60 anos, imaginemos a sala cheia, nos tempos sem televisão, e uma criança que recita. Apresenta aos espectadores um drama cantado. Essas meninas de ontem, dramatizando cenas de amores correspondidos ou fracassados, realizavam um desejo que as acompanhava sempre: serem adultas?

$O$ que realizavam as meninas dramistas do passado e as meninas do século XXI que dançam a dança da "bundinha"? Pré-exercitam capacidades maturacionais (Groos), fazem uso de material instintivamente herdado de antepassados (Stanley Hall), ou realizam o desejo de serem adultas (Freud)?

Ser uma dramista é aprender a sofrer, exercitando os esquemas inatos •de sofrimento? É lançar mão de uma herança instintiva de suportar o sofrimento? E disso que se trata? Por que o sofrimento é escolhido como tema de brincar ontem e hoje? Não é estranho uma criança exercitar o drama, os desencontros, os desenlaces, as misérias da vida cotidiana?

Ouvindo esses relatos do passado, pareceu-nos que o recitado fala de um certo entendimento da vida ou mesmo de uma tentativa de vir a entender o mundo adulto. Refletindo sobre as confissões de uma infância com dramas cantados e sem televisão, arriscamos afirmar que as meninas apresentavam aos adultos e demais espectadores o que entendiam do que somos ao longo da vida e quais os segredos dela, das conquistas, dos amores, das seduções, do desejo que pulsa em nós e nos faz sujeitos.

Recitando dramas em vida, a criança está transformando pulsões em cultura? As pulsões sexuais infantis eram transformadas em letras, músicas, ritmos e coreografias aprendidas pelas crianças e apresentadas aos adultos? As pulsões viravam trabalho?

Ouvimos os dramas cantados, dentro de uma velha cozinha, atacada por cupim, na voz de uma exmenina-atriz, representante de uma infância passada há várias décadas, que resiste a começar a falar, a cantar, por causa dos cupins ou de um probleminha na garganta, causado por ter comido caranguejo. Mas, aos poucos, vai cantando, rindo, lamentando todas essas "vicissitudes" da memória, que fazem os dramas ficarem "quebrado velho" (não tão lineares que faltem frases, que palavras sejam esquecidas, que palavras sejam trocadas). Um desejo de descobrir os lapsos, que vai das tentativas até o desespero por não conseguir rápido!

Em alguns momentos nos parece que ela faz agora, já não sendo mais uma dramista, o entendimento das coisas; nas pequenas explicações que vai dando, vai completando as lacunas, vai dando um conteúdo mais manifesto ao que lhe foi oferecido na infância em "barras", não de chocolate, mas até de doce e também de amargo, e condensado, como um sonho.

A nossa entrevistada, envolvida com dores e atribulações domésticas, entregava-se ao riso, ao comentar as 
"besteiras" da infância e compará-las com as "durezas" da vida adulta. Os risos foram aparecendo, além dos apelos a Deus ou a Jesus Cristo pelas vicissitudes da sua memória, pelos esquecimentos das falas dos dramas de sua infância. Percebemos que, diante dos lapsos, havia uma vontade de redescobrir os dizeres (como é mesmo que se recitava? $O$ que dizia a mocinha? O que declarava o Corcunda? O que pedia a mãe?).

E bem verdade que a retiramos da sua condição de mulher de mais de 70 anos, aposentada, solitária e povoada de lembranças. Além de estar sufocada com os problemas que lhe haviam causado certos visitantes indesejáveis: os cupins. Aquela cozinha-cenário dos seus depoimentos estava ameaçada pela ação de tais invasores!

Ofertamos a essa menina-dramista nascida em 1925 a condição de memorialista, de alguém que tem o legado de registrar o passado do brincar de uma antiga infância em Guriú; fomos retirando-a do imenso leque de lamentações pelas dores, dando-lhe a palavra e restituindo-lhe o sorriso que vinha lá da infância (ou desse lembrar).

E nos recitou o drama do "Corcunda"...

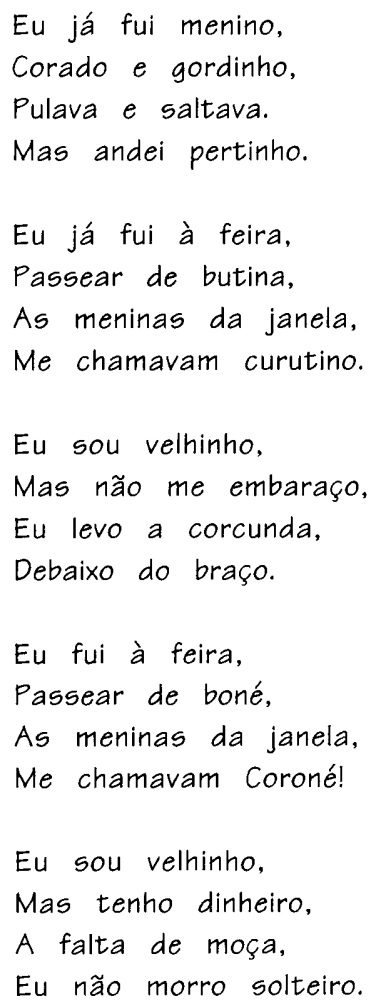


Ao nos contar e cantar esse drama, nossa entrevistada ri da certeza de o corcunda arrumar uma moça. Que lições sobre origem, vida, sexo e morte estariam entrelaçadas nesses dramas que imitavam a vida? As novelas mexicanas, atuais e dramatizadas pelas meninas, trazem as mesmas intenções simbólicas? O que havia nessas reproduções de um "velho", a dizer que já foi menino, e que ia além de treinar habilidade inata? Os dramas falam da vida? Representar as "coisas" dramáticas da vida ajudaria a acalmar nossos desânimos diários? O que é que esse corcunda apresenta a mais na vida, para saber vivê-la assim com tantas certezas, que nós não temos no cotidiano?

Pensemos nessas meninas-dramistas e no que as animava! Esquecendo a obsessão moderna de pré-exercitar ou testar capacidades herdadas, o que pode ser esse brincar? Seria um deslocamento do desejo de satisfação sexual direta infantil, que dá "lugar à satisfação sublimada, artística, por exemplo, graças ao prazer intermediário de gratificação narcísica do artista. É realmente o narcisismo do artista que condiciona e favorece a atividade criadora de sua pulsão sublimada"? (Nasio, 1991, p.85).

A psicanálise afirma-nos que os desejos inconscientes aparecem "disfarçados". Freud lembra-nos que reprimir os desejos inconscientes nos faz perder "fontes de energia mental que (...) teriam sido de grande valor na formação do caráter e na luta pela vida. Conhecemos uma solução muito mais conveniente, a chamada 'sublimação', pela qual a energia dos desejos infantis não se anula, mas, ao contrário, permanece utilizável, substituindo-se o alvo de algumas tendências por outro mais elevado, quiçá não mais de ordem sexual. Exatamente os componentes do instinto sexual caracterizam-se por essa faculdade de sublimação, de permutar o fim sexual por outro mais distante e de maior valor social. Ao reforço de energia para nossas funções mentais, por essa maneira obtido, devemos provavelmente as maiores conquistas da civilização" (Freud, 1910, p.59).

A sublimação age no brincar infantil, e os dramas cantados de Guriú reproduzem um mundo por entender (qual é o "obscuro" desejo que anima a vida adulta?).

As crianças de hoje e de ontem, habitantes dessa localidade litorânea, nos indicaram que o brincar responde a algo que realiza um desejo que percorre a infância inteira: o desejo de ser adulto (Freud) e de compreender o desejo que anima os seus adultos significativos (seja em tempos sem televisão, com dramas a representar, seja com a reprodução das dancinhas de Xuxa ou Carla Perez).

Pareceu-nos que as meninas de hoje (que "imitam" artistas da televisão) e os relatos das meninas de ontem (encenando os seus dramas) realizam uma forma de entender o mundo que as cerca. $\mathrm{Na}$ hora do faz-de-conta, repetem palavras pronunciadas por perso- 
nagens das novelas, dançam a dança da "bundinha" (referência ao grupo musical baiano), cantam músicas de cantores de sucesso nos meios de comunicação.

Enfim, atualmente, tentam entender o encantamento dos adultos presos à tela da televisão. É possível "profetizar" que essas danças não cheguem ao verão seguinte, mas "noticiam" algo de um desejo infantil disfarçado de "bailarina" Carla Perez, que, na época da nossa passagem, em 1998, ainda era do grupo E o Tchan.

A leitura desses dramas cantados traz-nos a "flutuação" do sentido das palavras, essa capacidade de metamorfose do dito e que se refere ao não-dito, que desloca os dizeres para além dos significados, resgata significantes, leva-nos (com esses dramas cantados) para além do lugar do ser pensante (não é só pré-exercitação de capacidades cognitivas ou uso de herança instintiva). Devemos nos exercitar para não procurar só elementos lógicos nesses dramas. Há algo aqui do recalcado, do inconsciente e do desejo que não sabemos onde está, nem o que quer mesmo de nós.

Santa Roza e Reis afirmam que não podemos negar as ligações "entre o desejo inconsciente e fantasias com o brincar. O que nos parece problemático é a caracterização de uma manifestação essencialmente imaginativa e consciente como algo no qual se pudesse vislumbrar imediata e diretamente a sexualidade infantil" (Santa Roza \& Reis, 1997, p.81).

Crianças brincam de ser. E configuram-se aí não só as impossibilidades próprias da idade (já que não alcançaram ainda a puberdade); elabora-se também, em cada faz-de-conta, que se é dona de casa, ou o marido que vai trabalhar, uma possibilidade de melhor compreender o que ainda viverão, ou seja, a vida adulta e o desejo que a anima (Jerusalinsky \& Tavares, 1992, pp.6-9; Freud, 1908).

O exame das considerações da psicanálise sobre o brincar infantil revelou-nos que, para além de pré-exercício de capacidades maturacionais e de lançar mão da herança instintiva dos ancestrais, a brincadeira de uma criança fala-nos da vida. Trata-se de uma "arte" infantil que constitui o sujeito. É possível encontrar nas brincadeiras infantis os traços, as marcas, os esboços, os detalhes desse fazer-se alguém que deseja, desse fazer-se sujeito do desejo.

Santa Roza defende uma "dimensão ontológica do brincar como um movimento constituinte da realidade psíquica, capaz de promover o estabelecimento das relações do sujeito com a realidade. Longe de ser apenas uma expressão da sexualidade infantil, ele promove a tessitura da fantasia, reconciliando o inconciliável, como lugar da ilusão, da realização do desejo" (Santa Roza, 1993, p.144).

Nos tempos atuais, já que nos agrada viver sonhando com a vida dos atores, limitamo-nos a ver nossas crianças imitando, com 
todo o jogo de sensualidade, as atrizes da última hora. Livres do passado, das dívidas com os ancestrais, estamos sofrendo com as dores dos emergentes da TV.

Quando ouvimos as crianças a falar ou a dançar/cantar as danças da moda, percebemos que havia televisões ligadas e olhos dos adultos encantados com toda essa maravilhosa vida colorida, alegre e encantadora. As crianças não podiam desconhecer esses brilhos nos olhos dos pais! As crianças podem supor que algo que anima o desejo do adulto se origina das telas.

Freud revela-nos o quanto a criança vai desejar entender e viver esse mundo adulto e dedicará as suas brincadeiras a esse intento: fazer de conta que é adulta. Realizar esse desejo de ser adulto, ainda na sua impossibilidade, pelo brincar (Freud, 1908, 1344).

Brincando, portanto, as crianças realizam um persistente desejo, que orienta suas atividades infantis, entre elas a brincadeira. $\mathrm{E}$ esse desejo é o desejo de ser gente grande.

$\mathrm{Na}$ obra de 1908, Freud escreve sobre as similaridades entre o poeta e a criança que brinca; e julga que as crianças reproduzem, à hora em que brincam, aquilo que vão conhecendo sobre a vida dos adultos que os cercam. Seriam os dramas cantados representados pelas vovozinhas de Guriú (quando eram crianças...) uma forma de mostrar aos adultos seus próprios conflitos humanos transformados em arte, arte de representar? Essas meninas-atrizes realizavam um desejo que as perseguia, o de serem adultas.

Durante toda a nossa trajetória, nossos faróis foram as entrevistas, as anotações de campo, um suspiro ou um sorriso de um adulto - desses suspiros e sorrisos inesquecíveis na hora da narração de suas histórias de vida. A nossa escrita é marcada por lembranças de Guriú, dos dias passados por lá e do que essas permanências nos revelaram sobre o brincar infantil de ontem e de hoje. Lançamos, ao longo deste trabalho, perguntas e reflexões que nos "transplantavam" para aquela praia do oeste cearense.

Escolhemos o caminho da crítica aos determinismos psico(bio)lógicos que recheiam as teorias sobre o brincar e que terminam exercendo influência sobre a educação (quando se pretende realizar uma nova metodologia que envolva as brincadeiras infantis), sobre o estabelecimento das compras de brinquedos dos pais (que devem seguir padrões científicos), sobre o "gigantismo" da televisão invadindo as brincadeiras das crianças e passando a ilusão de sermos pessoas falando a mesma língua dentro de um país cheio de Guriús com tantas especificidades, dançando a mesma dança da Xuxa ou da Carla Perez e chorando diante dos dramas dos personagens das novelas. 
Findada a pesquisa em 1998, pensávamos que não havia qualquer possibilidade de suspender o uso das televisões nesse recanto junto ao mar. As lutas de dois irmãos que chamavam a atenção da população não podiam mais ser a principal atração do domingo, $e$ as meninas não apresentavam mais os dramas cantados. Os domingos eram os dias consagrados a Xuxa e Faustão.

A televisão em Guriú, tal e qual nas grandes e médias cidades deste país, montou um "império" eficiente e lucrativo para quem dela faz comércio. Produtos e marcas estão diante dos olhos atentos à tela.

Entretanto, sentimos a falta de outras marcas; que, tanto no passado quanto no presente, são funções dos adultos. Faltam as marcas simbólicas, e delas a televisão não tem conseguido dar conta. Do que podemos ver em Guriú, impunha-se uma urgência: mesmo que os brilhos dos dramas cantados não possam ser comparados ao esplendor da $\mathrm{TV}$, é urgente recuperar a memória dos pais (pois essas marcas simbólicas aí estão).

Julgamos que as manifestações culturais de Guriú, longe das "dancinhas" que a televisão nos apresenta, precisam ser revividas. Se um dia for possível fazer uma espécie de "caça aos tesouros perdidos no fundo do mar", que banha Guriú, algo diferente podia começar a ser lançado. E que essa movimentação não devia demorar a acontecer: este foi o voto de fé que impulsionou a escrita deste trabalho.

Não estávamos dispostos a arriscar o pescoço propondo algo parecido com o desligamento de todas as televisões, em prol do "pleno desenvolvimento infantil". É impossível apagar, da noite para o dia, o encantamento que a TV desencadeia. Prevíamos que seria possível retornar a Guriú e colaborar para que as diferenças entre o brincar de ontem e de hoje pudessem dialogar. Acreditávamos nessa possibilidade de diálogo entre o passado e presente, entre netos e avós.

Defendíamos que talvez fosse possível realizar junto aos educadores, aos nossos memorialistas e aos jovens e crianças algo que fale em nome da preservação de uma memória cultural, que não iremos questionar se é regional ou universal, se chegou de barco ou veio a pé, mas que faz parte dos relatos dos mais velhos e que tem a ver com esses brinquedos usados no passado, com os dramas cantados exibidos antigamente e que remontam ao cenário das brigas dos dois irmãos de Guriú que coloriam os domingos sem TV.

A escola, esse antigo "templo" do saber e da memória deixada pelas mais antigas gerações que nos antecederam, talvez pudesse ser um lugar apropriado para esses encontros ao redor das alegrias do brincar de avós, pais e crianças. 
Crianças atuais poderiam ser preparadas pelas avós para realizar uma apresentação pública de um dos "velhos" dramas-cantados, em alguma festividade importante para essa comunidade. Nesse pequeno encontro, seriam ensaiadas algumas marcas, que poderiam desencadear a redescoberta dos potenciais criativos, de uma "intervenção" adulta junto ao brincar das crianças e de gente de "carne e osso" transformando sintoma em criação artística. E fazendo já alguma diferença, movimentando corpo e cabeça, de forma criativa, agora estacionados a ver somente os personagens "emergentes" da telinha.

Visitamos a comunidade de Guriú em janeiro de 1998, e nos dedicamos às pesquisas bibliográficas e depois a escrever a dissertação. Até o momento em que pegamos o caminhão de volta, e decretamos o fim da pesquisa, era comum encontrar meninas imitando Carla Perez, repetindo frases ditas nas novelas, investindo-se do papel de boas ou más personagens das programações televisivas.

As palavras que eram ditas na hora do faz-de-conta eram da ordem do transitório, do passageiro, da última moda e dos personagens do momento. Nada havia que comemorasse o passado, que lembrasse feitos dos antepassados. Somente as falas das suas avós.

Naquele momento os dramas cantados, saberes orais de Guriú, já não eram mais encenados. Refletindo sobre a realidade em que habitamos, neste fim de século, em Guriú ou em outro recanto qualquer, concordamos com Calligaris em que "triunfa a conviç̧ão de que o real, biológico ou químico que seja, oferece ou oferecerá as respostas para todos os nossos problemas. Nisso não há nada surpreendente. Nossa cultura deixa aos poucos - ou mesmo aos muitos - de se referir a valores simbólicos, exalta a autonomia do indivíduo, mas - paradoxo previsível - chora sobre os belos tempos das certezas perdidas e conclama, com razão, que faltam critérios éticos. A época em que vivemos oferece duas opções substitutivas: em vez de critérios, encontramos imagens positivas ou negativas de homens ou mulheres com os quais é recomendado identificar-se ou não. E, em vez de sabedorias tradicionais, encontramos a autoridade do que é apresentado como a irresistível evidência do real, biológico, químico, anatômico e, por conseqüência, científico. Nunca foi tão explícita a preferência social por qualquer tipo de simplificação que pareça resolver cientificamente nossos dramas cotidianos" (Calligaris, 1996, p.100).

Pois as falas das "vovozinhas" de Guriú parecem fazer renovados ecos! Algo se re-significou na presença dos adultos significativos, junto ao brincar infantil. Pareceu-nos que falar de infâncias passadas, ainda que tendo o volume alto das produções televisivas como um dos empecilhos do caminho, fez renascer os dramas cantados. 


\section{Artigo}

Em 1999 foram encenados dois dramas, coordenados por uma obstinada professora aposentada, exausta por tentar produzir e provocar marcas que andem além das passageiras marcas dos produtos que Xuxa, Carla Perez e os demais emergentes anunciam.

Ela avisa que a empreitada é dura, os desafios são imensos. Em alguns momentos tem vontade de desistir. Mas vai tentando! As meninas querem adaptar os dramas cantados às danças da Xuxa. Ela insiste em que devem incorporar personagens, ser atrizes, representar. Ir além da reprodução da dança da bundinha. E a luta continuará? Torcemos para que sim!

Querendo ocupar o seu tempo de aposentada, essa mulher parece nos provar que os adultos precisam semear idéias, deixar marcas simbólicas e ajudar a contornar a ordem "estabelecida". Ordem que insiste em prometer-nos uma felicidade que se compra com cartão de crédito, por telefone, e que nos redime das tristezas, do mal-estar e nos exime da responsabilidade para com os referentes simbólicos oferecidos por essa "gente grande" que nos cerca quando ainda somos crianças, e levamos boa parte do tempo a brincar.

\section{REFERENCIAS BIBLIOGRÁFICAS}

Calligaris, C. (1996). Crônicas do individualismo cotidiano. São Paulo, SP: Ática.

Freitas, M. G. F. (1999). Da psico(bio)logia do jogo infantil ao desejo de fazer de conta que é adulto - Um estudo sobre o brincar infantil. Dissertação de Mestrado, Faculdade de Educação, Universidade de São Paulo, São Paulo, SP.

Freud, S. (1908). El poeta y los sueños diurnos. In Obras completas, $4^{\mathrm{a}}$ ed. (L. López-Ballesteros y de Torres, trad.) (Tomo II, pp.1342-8). Madri, Biblioteca Nueva, 1981.

-_-- (1910). Cinco lições de psicanálise - Contribuições à psicologia do amor (D. Marcondes \& J. B. Corrêa, trads.). Rio de Janeiro, RJ: Imago, 1997.

Itard, J. (1980). Memória acerca dos primeiros progressos de Victor de Aveyron. In L. Malson, As crianças selvagens: mito e realidade. Porto: Civilização.

Jerusalinsky, A. \& Tavares, E. E. (1992). O brincar é a realidade - Acerca de algumas questões de atualidade na psicanálise da infância. AAPOA Boletim, 3 (7), 6-9.

Lajonquière, L. de (1997). Dos "erros" e em especial daquele de renunciar à educação: Notas sobre psicanálise e educação. Estilos da Clínica: Revista sobre a Infância com Problemas, 2 (2), 27-43.

Linaza, J. L. (1992). Jugar y aprender. Espanha: Allambra Longman.

Malson, L. (1980). As crianças selvagens: mito e realidade (C. C. Rodrigues, trad.). Porto: Civilização. 
Mannoni, M. (1977). A educação impossível (A. Cabral, trad.). Rio de Janeiro, RJ: Francisco Alves.

Nasio, J. D. (1991). Lições sobre os 7 conceitos cruciais da psicanálise. Rio de Janeiro, RJ: Zahar.

Santa Roza, E. (1993). Quando brincar é dizer - A experiência psicanalítica na infância. Rio de Janeiro, RJ: RelumeDumará.

Santa Roza, E. \& Reis, E. S. (1997). E agora eu era o herói... O brincar na teoria psicanalítica. In Daanálise na infância ao infantil na análise. Rio de Janeiro, RJ: Contra Capa.

\section{NOTAS}

1 Da psico(bio)logia do jogo infantil ao desejo de fazer de conta que é adulto Um estudo sobre o brincar infantil é o título de nossa dissertação de mestrado. Realizamos a pesquisa de campo em Guriú (Ceará), nos anos de 1996, 1997 e 1998.

2 Visitamos Guriú em fevereiro de 2000 e tivemos a grata satisfação de saber que, enquanto escrevíamos a nossa dissertação, os dramas cantados voltaram espontaneamente a ser encenados. A pesquisa continua, e as alianças com a psicanálise nos trarão novas reflexões, leituras e escritas sobre o brincar.

Recebido em 03/2000. 